Fanum

Sociológico

\section{Forum Sociológico}

Série II

$19 \mid 2009$

As Forças Armadas numa sociedade em mudança

\title{
Jovens e Forças Armadas: contornos de uma nova relação num contexto de profissionalização
}

António Ideias Cardoso, Isabel Madeira, Francisco Sousa Marques, Cristina Poças Vilhena, Luís Vicente Baptista, José Manuel Resende e Paulo Antunes Ferreira

\section{OpenEdition}

12 Journals

Edição electrónica

URL: https://journals.openedition.org/sociologico/113

DOI: 10.4000/sociologico.113

ISSN: 2182-7427

Editora

CICS.NOVA - Centro Interdisciplinar de Ciências Sociais da Universidade Nova de Lisboa

Edição impressa

Data de publição: 1 junho 2009

Paginação: 25-36

ISSN: 0872-8380

\section{Refêrencia eletrónica}

António Ideias Cardoso, Isabel Madeira, Francisco Sousa Marques, Cristina Poças Vilhena, Luís

Vicente Baptista, José Manuel Resende e Paulo Antunes Ferreira, «Jovens e Forças Armadas: contornos de uma nova relação num contexto de profissionalização», Forum Sociológico [Online], 19 | 2009, posto online no dia 27 setembro 2012, consultado o 30 março 2022. URL: http:// journals.openedition.org/sociologico/113 ; DOl: https://doi.org/10.4000/sociologico.113

Este documento foi criado de forma automática no dia 30 março 2022.

(c) CICS.NOVA 


\title{
Jovens e Forças Armadas: contornos de uma nova relação num contexto de profissionalização
}

\author{
António Ideias Cardoso, Isabel Madeira, Francisco Sousa Marques, \\ Cristina Poças Vilhena, Luís Vicente Baptista, José Manuel Resende e \\ Paulo Antunes Ferreira
}

\section{As sociedades contemporâneas e o lugar das Forças Armadas}

1 É comum reafirmar-se o lugar proeminente ocupado pelas Forças Armadas nos EstadosNação modernos. Tal como outrora, esta instituição é considerada um pólo da expressão da soberania nacional.

2 Não obstante o desenvolvimento do processo de alargamento da Comunidade Europeia e das políticas que visam a constituição de outras modalidades de cooperação política e militar mais coordenada, a centralidade das Forças Armadas nacionais não é posta em causa. O mesmo se tem passado com o debate, ora mais generalizado, ora mais localizado, em torno do processo de profissionalização destas forças.

3 Apesar da aparente estabilidade nas funções e finalidades das Forças Armadas esta instituição está hoje sujeita a profundas transformações políticas e organizacionais. A profissionalização humana e material hoje em curso obriga a instituição a adoptar outros dispositivos e modalidades de acção, em particular quando está em causa o recrutamento de um número significativo de jovens para o cumprimento das suas missões internas e internacionais.

O reconhecimento por parte das Forças Armadas da importância deste processo exige dos seus quadros dirigentes uma outra forma de repensar as relações entre esta instituição e os grupos sociais que constituem a sua base preferencial de recrutamento. $\mathrm{Na}$ verdade, com a entrada em vigor da Lei do Serviço Militar aprovada em 1999, ficou definido o ano de 2004 como o fim da obrigatoriedade de cumprimento do serviço 
militar, passando as Forças Armadas portuguesas a assumir uma nova configuração em matéria de prestação de serviço e de relação com os jovens.

5 As alterações jurisdicionais operadas após a promulgação do referido quadro legal tiveram impactos na concepção do próprio conceito de Defesa Nacional que, por sua vez, se repercutiram no modelo organizacional, particularmente nas modalidades e dispositivos de recrutamento militar. Para manter um certo nível de relacionamento das Forças Armadas com a população e fomentar nesta o conhecimento dos temas associados à Defesa Nacional e às Forças Armadas foi concebido o Dia da Defesa Nacional (DDN). Em certo sentido, com esta implantação o Estado, por mediação directa do Ministério da Defesa Nacional, cria as condições para desenvolver um trabalho de reforço dos preceitos da cidadania, com a cooperação interessada e empenhada das Forças Armadas e das outras instituições estatais, junto das camadas jovens.

6 Este evento, cuja participação é obrigatória para os cidadãos do sexo masculino no ano em que completam dezoito anos de idade (e que em 2010 se generalizará a todos os cidadãos com 18 anos), tem como principais objectivos "sensibilizar os jovens para a temática da defesa nacional e divulgar o papel das Forças Armadas, a quem incumbe a defesa militar da República" (Artigo 11. da Lei do Serviço Militar N. 174/99 de 21 de Setembro de 1999). Por outro lado, a mesma Lei define o que deve ser incluído nesta sensibilização e divulgação:

"A sensibilização e divulgação (...) envolvem, designadamente, informação escrita descrevendo os preceitos constitucionais que se relacionam com a defesa nacional, os princípios gerais que se relacionam com as Forças Armadas, direitos e deveres dos cidadãos, assim como os objectivos do serviço militar e as diferentes possibilidades que se lhe oferecem durante e após o serviço militar, acções de formação sobre os objectivos da defesa nacional, sobre as missões essenciais das Forças Armadas, a sua organização, os recursos que lhes estão afectos e informação sobre as formas de prestação de serviço" (ibidem).

7 Em termos de estruturação deste evento, o Regulamento da Lei do Serviço Militar (Decreto-Lei n. . 289/2000 de 14 de Novembro) define no seu artigo 20., n.ำ 1, que "o Dia da Defesa Nacional ocorre nas unidades militares dos três ramos das Forças Armadas, na rede escolar de ensino e noutros equipamentos públicos com condições para o efeito, em data e demais condições a fixar por despacho conjunto dos Ministros da Defesa Nacional e das correspondentes tutelas". E no que respeita ao planeamento e execução, o artigo 21.. estabelece que "o planeamento e a concepção do DDN competem a uma comissão composta por representantes da DGPRM, dos três ramos das Forças Armadas, do Ministério da Educação e da Secretaria de Estado da Juventude" (ibidem), competindo a esta comissão definir os programas das acções de formação e as actividades a desenvolver. O Dia da Defesa Nacional aparece, assim, como o momento por excelência em que se efectiva a relação entre as Forças Armadas e os jovens, e daí que, apesar de os seus objectivos abrangerem áreas como a Cidadania e a Defesa Nacional em sentido lato, as temáticas de natureza mais militar tenham um lugar de destaque na sua estruturação.

8 É no decurso deste evento que se realiza o estudo que sustenta este artigo. Trata-se de um estudo que visa não só a avaliação do Dia da Defesa Nacional através da forma como é visto pelos seus participantes, aspectos que não fazem parte dos objectivos deste texto, mas também aferir o que pensam das Forças Armadas e da nova configuração que assume o modelo de prestação de serviço militar. 
Os dados que se apresentam nos pontos seguintes foram recolhidos através de inquérito por questionário aplicado no ciclo do Dia da Defesa Nacional de 2006/2007, abrangendo cerca de 54000 participantes.

\section{Representações dos jovens sobre as Forças Armadas} pela Psicologia Social, não estão ausentes da tradição sociológica. Desde a fundação da investigação sociológica - com autores como Durkheim, que atribuiu às representações sociais um estatuto sociológico, considerando-as capazes de se constituir em objecto de estudo autónomo, ou Max Weber, que fez deste conceito um quadro de referência e um vector da acção dos indivíduos, descrevendo um saber comum e tendo o poder de antecipar e predizer o seu comportamento -, até à actualidade, têm sido inúmeras as correntes de investigação que utilizam e definem o conceito de representações de forma diversificada.

11 Contudo, não é a caracterização dessa diversidade que se pretende desenvolver no âmbito deste texto. Pretende-se apenas chamar a atenção para o facto de as representações serem um elemento essencial quando se trata da identificação e interpretação de dispositivos de acção dos sujeitos face a um objecto representado numa determinada situação ou contexto. Sendo um elemento adjuvante dessa mesma acção, as representações constituem referenciais explicativos, comunicacionais e operatórios com funcionalidades práticas diversas, de entre as quais se destacam a organização significante da realidade, a possibilidade de realizar actos comunicacionais, a produção de diferenças e distinções entre grupos sociais e a orientação de comportamentos e atitudes face ao objecto representado. São estes os preceitos que fundamentam a importância conferida ao estudo das representações sobre as Forças Armadas e com os quais se pretende proceder ao seu desenvolvimento. Se se pretende mensurar a atractividade que as Forças Armadas, e as profissões que lhes são inerentes, têm junto de um determinado grupo populacional - neste caso, os jovens de sexo masculino que perfazem 18 anos -, ou identificar o lugar que é conferido às Forças Armadas na estruturação de trajectórias de cariz profissional, tal implica que se proceda ao questionamento das representações que este grupo populacional veicula a seu respeito. Por outro lado, pode também dizer-se que a própria dinâmica da modernidade e a consequente evolução das estruturas de Forças Armadas (ou seja, a sua profissionalização) implicam, por parte destas, uma atitude de procura constante de legitimidade institucional. Como afirma Battistelli (Battistelli, 2004), as instituições, não só as Forças Armadas, são investidas de um processo de secularização, perdendo, na sequência do mesmo, aquela aura de sacralidade que no passado lhes garantia a adesão dos indivíduos. Por mais elevado que possa ser o fim perseguido por cada uma, as instituições têm, cada vez mais, de procurar no dia-a-dia a manutenção da sua legitimidade.

12 Assim, o desenvolvimento deste ponto incide sobre a análise dimensional aos conteúdos das representações sobre as Forças Armadas, construídas pelos jovens participantes no Dia da Defesa Nacional, abarcando, em primeiro lugar, a dimensão institucional, que engloba a apreciação da sua utilidade e eficácia e o grau de confiança que lhes é atribuído. Em segundo lugar, é abordada a dimensão profissional, incidindo sobre a 
forma como são caracterizadas enquanto oportunidade profissional e a apreciação do que proporcionam neste domínio.

\section{Representação institucional das Forças Armadas}

13 A definição e operacionalização desta dimensão de conteúdo das representações visa aferir qual a imagem institucional veiculada pela população inquirida. Para o efeito foram utilizados quatro indicadores, sendo o primeiro referente à apreciação da utilidade das Forças Armadas, o segundo à eficácia destas no cumprimento das suas missões, o terceiro ao papel que desempenham na formação dos jovens e o último referente ao grau de confiança nelas depositado. Pensa-se que esta dimensão de conteúdo das representações se pode constituir como um elemento explicativo importante no que concerne ao diagnóstico da relação dos jovens com as Forças Armadas, para o qual este trabalho visa contribuir. Em termos de resultados, importa destacar que todos os indicadores de representação utilizados nesta dimensão obtiveram valores de apreciação bastante positivos, como se pode verificar no Gráfico 1. De entre eles, a utilidade aparece num lugar de destaque com um valor médio de 5,66, seguida da eficácia e da confiança, com 5,41 e 5,39 respectivamente, ficando o valor mais baixo desta dimensão para o papel que desempenham na formação dos jovens $(5,17)$, mas ainda assim bastante positivo.

Dada a importância desta dimensão das representações como tradutora da relação dos jovens com as Forças Armadas, foi desenvolvida uma análise mais aprofundada, procurando, acima de tudo, determinar quais os factores que os fazem variar e qual o sentido que essa variação assume, considerando para o efeito o nível de escolaridade dos inquiridos e a sua condição sociofamiliar. Contudo, como os dados de cada um dos indiciadores evidenciaram um comportamento semelhante, optou-se neste texto por proceder à construção de um índice com o intuito de sintetizar a informação.

Gráfico 1: Representações Institucionais das Forças Armadas'

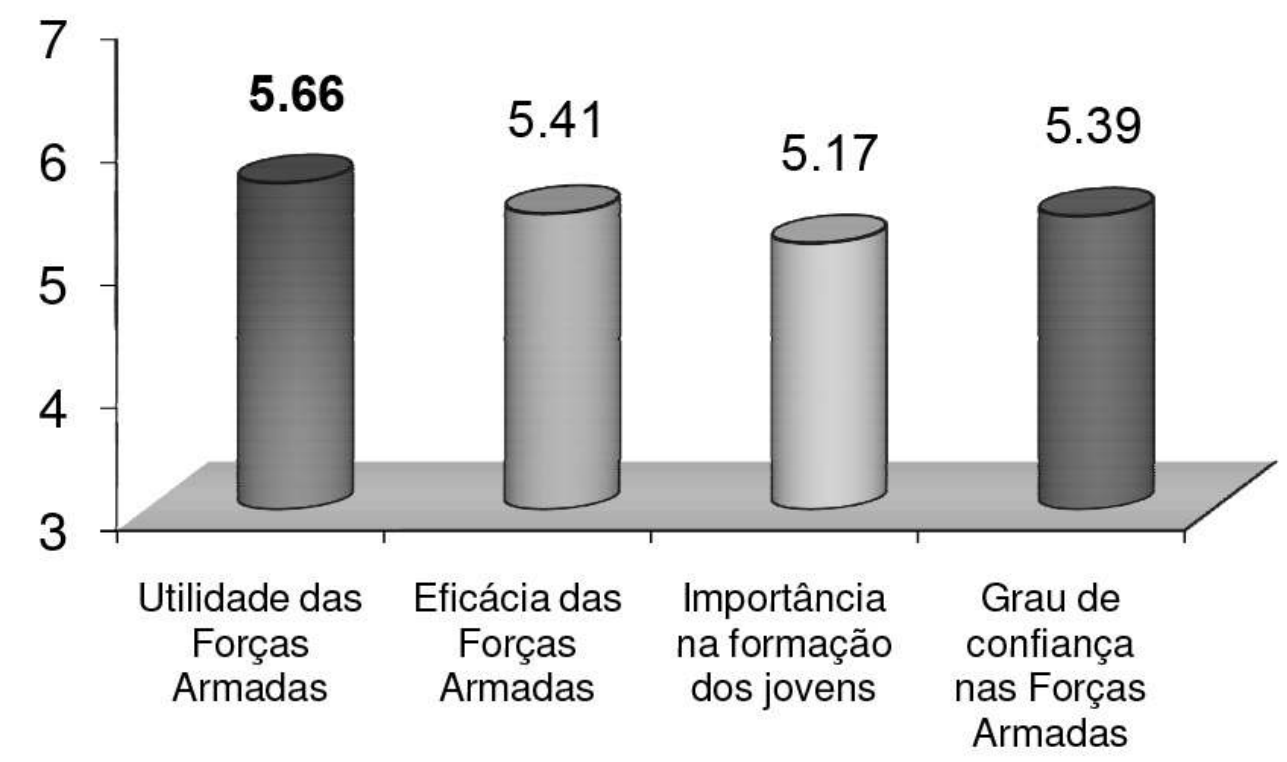

FONTE: MDN/DGPRM - BD DDN: 04/07 
Os resultados, expressos no Gráfico 2, permitem destacar, em primeiro lugar, a significativa positividade do próprio índice (Média=5,39) e, em segundo lugar, a positividade das representações institucionais em todos os níveis de escolaridade. No que concerne às características da associação entre as duas variáveis, pode dizer-se que apresenta uma intensidade moderada, estatisticamente significativa e de sentido negativo, dado que, à medida que aumentam os níveis de escolaridade, é menor o valor médio atribuído às representações de dimensão institucional. Relativamente às diferenças entre níveis de escolaridade, apenas não se revelaram estatisticamente significativas as que se verificam entre quem está no $8 .^{\circ}$ ano de escolaridade ou inferior e quem está no 9.ํ ano, sendo todas as outras de considerar.

Gráfico 2: Índice de Representações (dimensão institucional), por Nível de Escolaridade

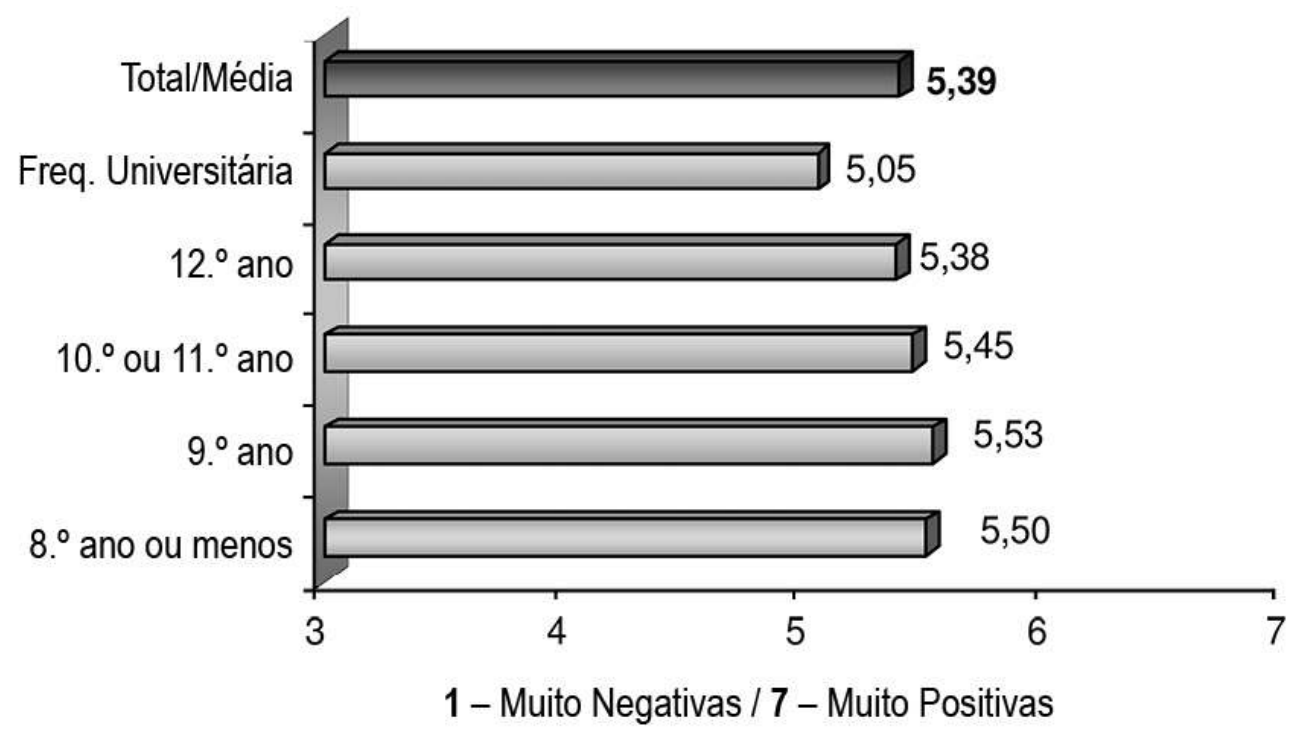

$f=230.129 ; p=0.000$

FONTE: MDN/DGPRM - BD DDN: 04/07

Se do ponto de vista da condição sócio-familiar se considerar a escolaridade dos pais ou o nível de rendimento, o padrão de associação não difere do anteriormente traçado, nem no que concerne à intensidade (moderada), nem quanto ao sentido (negativo).

\section{Representação das Forças Armadas enquanto oportunidade profissional}

17 No que concerne a esta dimensão de representação das Forças Armadas, do ponto de vista analítico foram abordadas as questões da atractividade do emprego proposto pelas Forças Armadas, complementadas com questões que permitem aprofundar o conhecimento sobre a forma como os jovens em estudo caracterizam este tipo de emprego.

18 Iniciando a análise pela forma como os jovens caracterizam o emprego proposto pelas Forças Armadas, pode dizer-se que os dados obtidos e constantes do Quadro 1 apontam para pistas de reflexão com algum interesse, que entroncam na especificidade com que este emprego é apreciado. Em primeiro lugar, os jovens destacam que se trata, acima de 
tudo, de um emprego ao serviço da pátria $(5,72)$, ou seja, um emprego que, além de estar associado a uma organização e, consequentemente, a um determinado grupo profissional, está ao serviço do país. Estes dados parecem revelar uma grande identificação das Forças Armadas com o interesse nacional, pois, mesmo quando se está a abordar questões concretas como as características de um emprego, ressalta como associação mais forte nas representações dos jovens o "serviço da pátria". Aliás, por este mesmo prisma pode interpretar-se o facto de os jovens não considerarem maioritariamente que um emprego nas Forças Armadas seja um "emprego como outro qualquer". Estes dois indicadores analisados em conjunto parecem reforçar a ideia de que os jovens vêem o emprego nas Forças Armadas como um emprego com características específicas, que ultrapassam a simples relação laboral entre empregador e empregado.

Quadro 1:Definição de um emprego nas Forças Armadas

\begin{tabular}{|l|l|}
\hline Característica & Média $^{2}$ \\
\hline Um emprego ao serviço da pátria & 5,72 \\
\hline Um emprego atractivo & 5,41 \\
\hline Um emprego com prestígio & 5,21 \\
\hline Um emprego que dá mais regalias que os outros & 5,19 \\
\hline Um emprego bem pago & 5,01 \\
\hline Um emprego seguro & 4,85 \\
\hline Um emprego que não exige experiência profissional & 3,35 \\
\hline Um emprego como outro qualquer & 3,12 \\
\hline Um emprego que não exige muitos conhecimentos & 3,11 \\
\hline
\end{tabular}

FONTE: MDN/DGPRM - BD DDN: 04/07

19 Seguidamente, os jovens destacam o facto de se tratar de um emprego atractivo $(5,41)$, o prestígio desse emprego $(5,21)$, bem como o facto de oferecer mais regalias que outros empregos $(5,19)$. Características como emprego bem pago $(5,01)$, ou emprego seguro $(4,85)$, também tiveram um valor de concordância que se pode considerar positivo, mas inferior aos anteriormente representados.

20 À semelhança do que foi feito para a dimensão institucional, os principais indicadores utilizados para analisar a representação das Forças Armadas enquanto oportunidade profissional foram também sintetizados num índice, para melhor representar os vectores de análise aqui explorados. Neste sentido, este índice resulta da apreciação da atractividade do emprego proposto pelas Forças Armadas em agregação com a apreciação do prestígio, das remunerações, da segurança e regalias que este confere, tendo sido submetido a testes de associação com a escolaridade dos inquiridos. Os resultados, expressos no Gráfico 3, na sua generalidade vão ao encontro dos padrões de 
associação que têm vindo a ser apresentados até aqui, destacando-se a positividade do próprio índice (média 5,13) e a variação que sofre por influência da escolaridade. A especificidade que apresenta prende-se com a não linearidade da sua variação em função dos níveis de escolaridade. Ou seja, entre os inquiridos que se situam nos níveis de escolaridade que vão do 8.. ano ou menos ao 12.. ano, a representação das Forças Armadas enquanto oportunidade profissional aumenta, caindo depois de forma algo acentuada quando se consideram os inquiridos que têm frequência de ensino superior.

GRÁfico 3: Índice de Representações (dimensão Oportunidade Profissional), por Nivel de Escolaridade

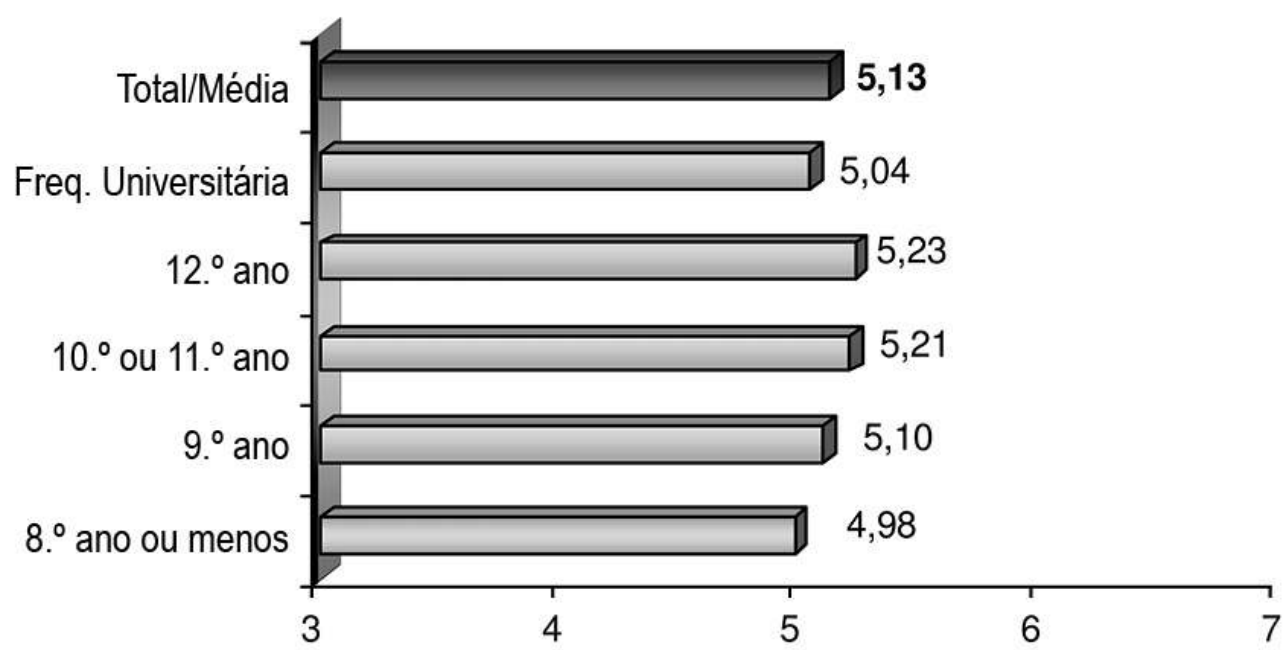

1 - Muito Negativas / 7 - Muito Positivas

\section{Os jovens perante a possibilidade de emprego em regime de voluntariado e de contrato nas Forças Armadas}

21 A questão do recrutamento é central no processo de profissionalização das Forças Armadas, processo este que inclui ainda outras dimensões, como sejam a fidelização de efectivos e a sua reconversão profissional para efeitos de reinserção na vida civil de uma forma profissionalmente activa. Se as Forças Armadas não conseguirem desenvolver a sua capacidade de atrair e recrutar novos elementos, nenhuma das outras fases do processo de profissionalização terá a devida sequência ou deixará de se defrontar com dificuldades.

A questão do recrutamento é naturalmente condicionada por um conjunto de variáveis de natureza muito distinta, associadas quer às características estruturais do novo modelo de serviço militar, quer à dinâmica conjuntural do mercado de emprego que se verifica na envolvente em que as Forças Armadas se inscrevem. No entanto, é possível afirmar que o recrutamento, em larga medida, depende da propensão manifestada pelo público-alvo que visa atingir, ou seja, depende da predisposição dos actores para agir em relação às propostas que lhes são apresentadas. 
Tendo o Dia da Defesa Nacional como objectivo principal a sensibilização dos jovens para a temática da Defesa Nacional e das Forças Armadas, não poderia deixar de ser encarado como um momento privilegiado para se aferir a atractividade da proposta de emprego disponibilizada pelas Forças Armadas à população em estudo. Assim sendo, este ponto tem como principal propósito estudar a predisposição para o ingresso nas Forças Armadas manifestada pelos jovens participantes no Dia da Defesa Nacional, procurando compreender como se caracteriza, em que motivações e objectivos se sustenta e quais os aspectos que a influenciam.

\section{Dimensão quantitativa da predisposição para o ingresso nas Forças Armadas}

Relativamente à predisposição dos jovens para ingresso nas Forças Armadas, os dados expressos no Quadro 2, em termos de dimensão quantitativa, demonstram que 52,87\% dos jovens participantes no Dia da Defesa Nacional se manifestam disponíveis, sendo a não pretensão assumida apenas por $25,2 \%$. Importa ainda salientar que $18,6 \%$ destes jovens manifestam uma posição indefinida em relação a esta matéria.

Quadro 2: Distribuição da posição dos jovens face ao ingresso no regime de voluntariado e de contrato (RV/RC)

\begin{tabular}{|l|l|l|}
\hline & Casos & $\%$ \\
\hline Não responde & 1851 & 3,4 \\
\hline Pretende ingressar & 29002 & $\mathbf{5 2 , 8 7}$ \\
\hline Não pretende ingressar & 13845 & $\mathbf{2 5 , 2}$ \\
\hline Não sabe & 10195 & 18,6 \\
\hline Total & 54893 & 100,0 \\
\hline
\end{tabular}

Em termos de contextualização temporal desta predisposição, os jovens foram inquiridos relativamente à probabilidade de ingressarem nas Forças Armadas nos 12 meses seguintes à participação no Dia da Defesa Nacional. A distribuição das respostas indica que cerca de $32,3 \%$ dos jovens que manifestaram a intenção de ingressar nas Forças Armadas pretendem efectivar esse ingresso nos 12 meses seguintes à participação no Dia da Defesa Nacional, sendo a dos restantes mais diferida no tempo.

\section{Dimensão qualitativa da predisposição para o ingresso}

Após ter sido realizada uma análise quantitativa da posição dos jovens face ao ingresso nas Forças Armadas, de seguida tentar-se-á compreender qual a escolaridade destes jovens, o seu percurso escolar e as suas aspirações escolares, onde residem, qual a sua origem socioeconómica e que tipo de representações têm sobre as Forças Armadas, 
tentando posteriormente compreender-se qual o contributo de cada uma destas variáveis na posição dos jovens face ao ingresso nas Forças Armadas.

\section{a) Dimensão Escolar. (escolaridade, aspirações escolares e situação actual)}

Relativamente a esta dimensão importa referir que não se pretende estudar a composição do ingresso em termos de escolaridade, mas antes compreender em que medida a escolaridade influencia a postura dos jovens face às Forças Armadas, verificando se existe aproximação ou afastamento em função de diferentes níveis de escolaridade. $\mathrm{O}$ Gráfico 4 permite concluir que a propensão para o ingresso é menor nos níveis de escolaridade mais elevados, comparativamente com os restantes. Pode mesmo dizer-se que se está perante uma relação linear e de sentido negativo. Tendo como referência o valor médio de predisposição para ingresso apresentado no início do capítulo $(52,4 \%)$, verifica-se que a propensão manifestada pelos jovens que se encontram a frequentar o ensino superior é menos de metade (23,5\%), ao passo que a que reporta aos jovens que têm até ao 10.\%/11. ano de escolaridade é superior a esse valor médio.

Gráfico 4: Distribuição da posição face ao ingresso pela escolaridade dos jovens

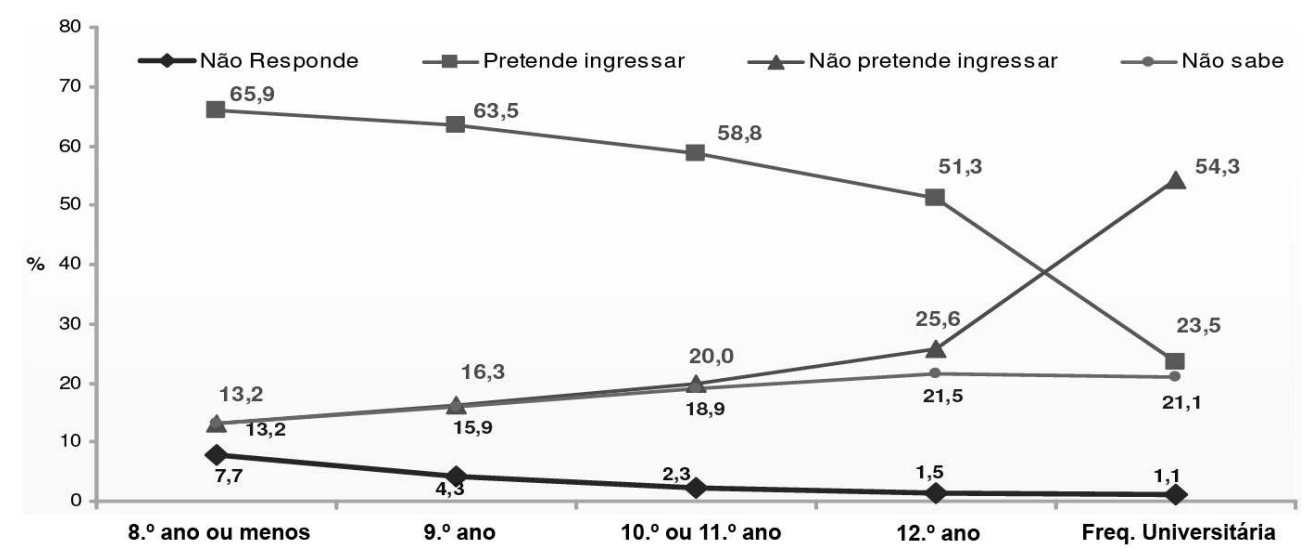

Phi $=.329 ; p=0.000 \quad N=52192$

FONTE: MDN/DGPRM - BD DDN: 04/07

Relativamente à situação actual dos jovens, verifica-se, através do Gráfico 5, que os jovens que se encontram a estudar são, de facto, os que revelam menor propensão para ingressar nas Forças Armadas, muito embora a percentagem de predispostos $(47,6 \%)$ possa ser encarada como muito significativa. Tal situação deve-se ao facto de, como foi visto anteriormente, junto dos jovens que se encontram a estudar em níveis iguais ou inferiores ao ensino secundário a predisposição para ingresso nas Forças Armadas ser bastante expressiva. 
Gráfico 5: Distribuição da posição face ao ingresso pela situação actual dos jovens

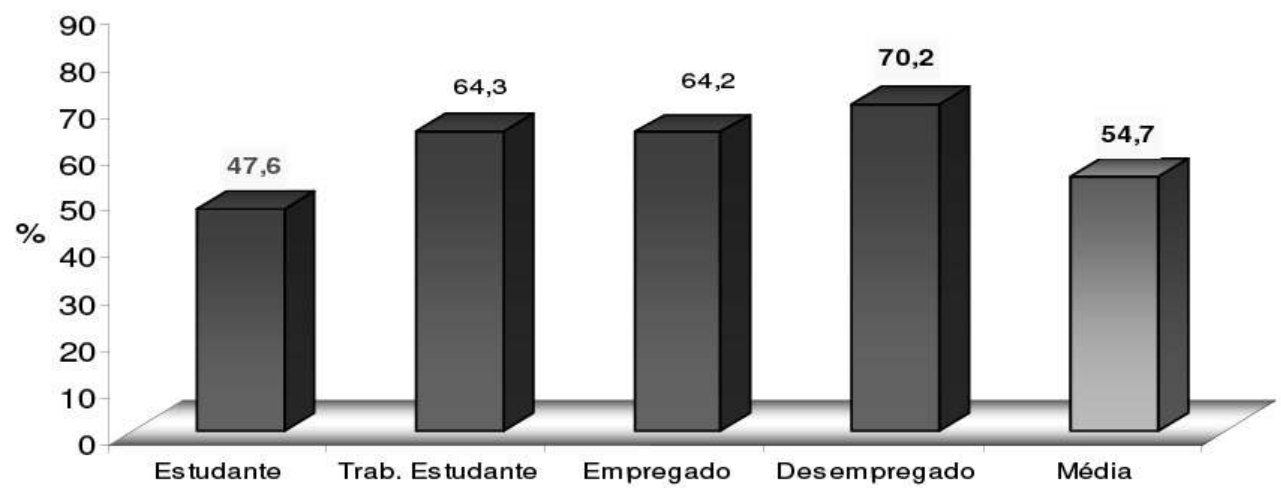

$\mathbf{N}=53042$

FONTE: MDN/DGPRM - BD DDN: 04/07

\section{b) Variáveis explicativas do ingresso}

No que concerne aos jovens que estão fora do sistema de ensino, ou pelo menos não o frequentam de forma exclusiva, a propensão para ingresso é superior à média, o que permite aferir que para este segmento populacional com contacto ou vivência de mercado de trabalho a proposta de emprego das Forças Armadas é atractiva.

Neste ponto, através de procedimentos estatísticos adequados, tentar-se-á não só quantificar a influência conjunta de todas as variáveis, mas também hierarquizá-las relativamente ao seu poder explicativo face à posição dos jovens relativamente ao ingresso nas Forças Armadas. Para o efeito, as variáveis até aqui enunciadas foram agrupadas em dimensões, cuja agregação se prendeu com a correlação estatística existente entre as mesmas. $\mathrm{O}$ Quadro 3 discrimina as variáveis incluídas em cada uma das dimensões, pela posição de entrada no modelo de análise (regressão linear múltipla - hierárquica, por blocos).

Quadro 3: Variáveis incluídas nas diferentes Dimensões de Análise

\begin{tabular}{|c|c|}
\hline Dimensões & Variáveis \\
\hline $\begin{array}{l}\text { Proximidade Simbólica às Forças } \\
\text { Armadas }\end{array}$ & $\begin{array}{l}\text { - Representações Institucionais sobre as Forças Armadas } \\
\text { - Representações sobre as FA enquanto oportunidade } \\
\text { profissional }\end{array}$ \\
\hline o Conteúdo do Dia da Defesa Nacional & $\begin{array}{l}\text { - Interesse da Cerimónia do Içar da Bandeira Nacional } \\
\text { - Interesse do Módulo } 1 \text { (Defesa Nacional e o papel das Forças } \\
\text { Armadas) } \\
\text { - Interesse do Módulo } 2 \text { (o Serviço Militar) } \\
\text { - Interesse da Demonstração de Actividades }\end{array}$ \\
\hline Escolar & $\begin{array}{l}\text { • Escolaridade } \\
\text { • Aspirações escolares }\end{array}$ \\
\hline
\end{tabular}




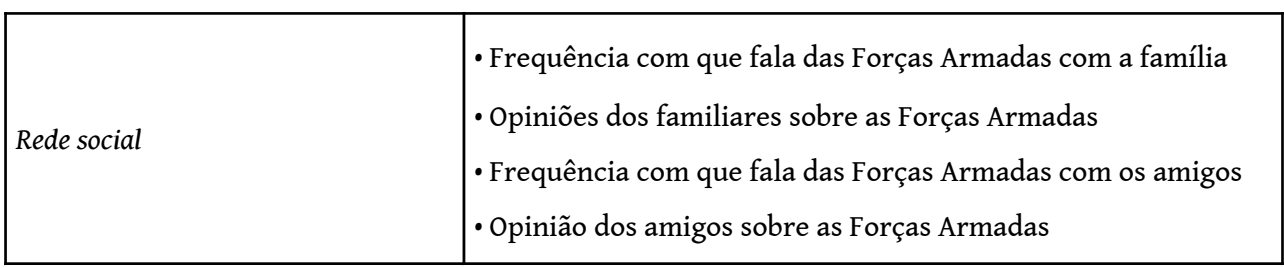

31 Como se pode verificar no Quadro 4, as dimensões consideradas reportam-se a aspectos relacionados com o percurso escolar do jovem, com variáveis relacionadas com a rede social e familiar e com aspectos relacionados com as percepções/representações que os jovens possuem sobre as Forças Armadas em que se incluiu, também, a apreciação do jovem sobre o Dia da Defesa Nacional. Os resultados obtidos revelam que as variáveis escolhidas têm uma importância significativa, sendo capazes de predizer $42,6 \%$ ( $\mathrm{p}$ < 0.000) da variação da predisposição dos jovens para o ingresso no RV/RC, o que é muito significativo em ciências sociais.

Em termos de importância de cada uma das dimensões utilizadas, verifica-se que a dimensão relativa à proximidade simbólica dos jovens face às Forças Armadas, traduzida pelas representações (institucionais e enquanto oportunidade profissional), é a que tem o maior poder preditivo, explicando por si só $29,7 \%(\mathrm{p}=0.000)$ da predisposição para o ingresso, facto que lhe confere uma preponderância significativa no modelo em causa. A segunda dimensão, respeitante ao conteúdo do programa do Dia da Defesa Nacional, que, recorde-se, era o contexto em que os dados foram recolhidos, tem uma importância preditiva da predisposição para ingresso que se pode considerar relativa, dado que explica apenas $1,8 \%(p=0.000)$ da variação desta. A terceira dimensão, que abarcava o nível de escolaridade e as aspirações escolares dos jovens inquiridos, apresenta uma capacidade preditiva significativa, mas também ela algo moderada, situando-se nos 5,2\%. Por último, a dimensão relacionada com a rede social dos jovens, abarcando a frequência com que as Forças Armadas são tema de conversa nessa rede, bem como a opinião respeitante a essas, apresenta uma capacidade preditiva estatisticamente significativa, mas moderada, com um valor de 5,9\%.

\section{A perspectivação do futuro profissional nas Forças Armadas}

Analisada a predisposição dos jovens para ingressar nas Forças Armadas, tanto em termos quantitativos como qualitativos, e identificadas as variáveis que têm maior capacidade explicativa sobre a variação dessa predisposição, importa agora verificar como esta se distribui pelos diferentes ramos e quais as características em que assenta. Neste sentido, verificar se subjacente à pretensão de ingressar está a escolha de um ramo em particular, analisar possíveis diferenças de características no que concerne aos jovens que são atraídos por cada um dos ramos, bem como se as expectativas profissionais e pessoais estão a ser projectadas com o eventual ingresso na Instituição parecem ser aspectos pertinentes.

Quadro 4: Resultados do Modelo de Análise de Regressão

\begin{tabular}{|l|l|l|l|l|l|}
\hline Variáveis & Beta & $\Delta \mathrm{R} 2$ & $\mathrm{~F}$ & $\mathrm{Gl}$ \\
\hline
\end{tabular}




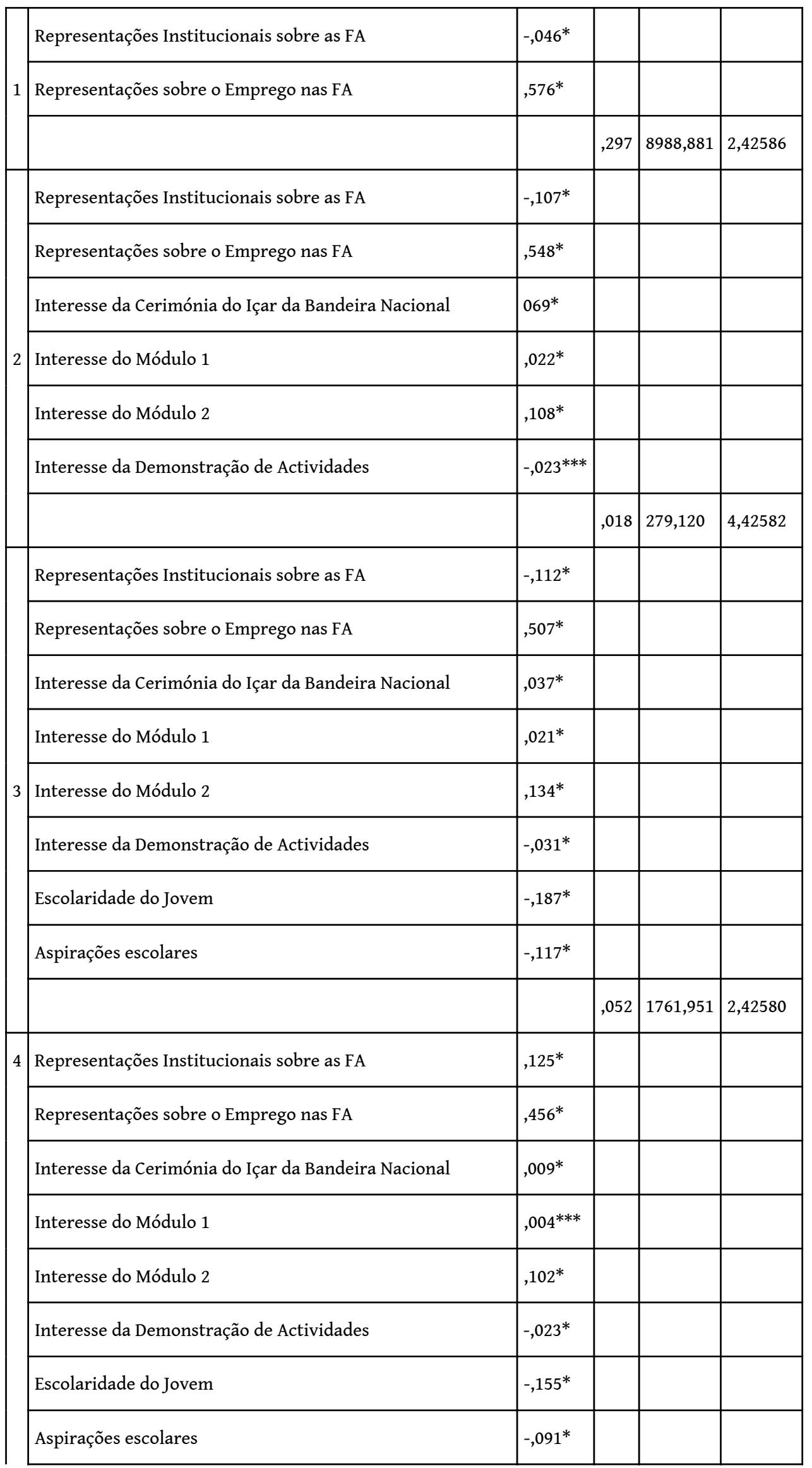




\begin{tabular}{|c|c|c|c|c|}
\hline Opinião dos amigos sobre as Forças Armadas &,$- 003 * *$ & & & \\
\hline Opinião dos familiares sobre as Forças Armadas &,$- 015^{* * *}$ & & & \\
\hline Frequência com que fala das Forças Armadas com os amigos &, $160^{*}$ & & & \\
\hline \multirow[t]{2}{*}{ Frequência com que fala das Forças Armadas com a família } &, $148^{*}$ & & & \\
\hline & & 059 & 1101,103 & 4,42576 \\
\hline R2 ajustado & & ,426 & 2638,626 & 12,42588 \\
\hline
\end{tabular}

${ }^{*} p<0.000 ; * \star<0.005 ; * \star \star>0.05$

FONTE: MDN/DGPRM - BD DDN: 04/07

\section{a) Distribuição da predisposição para o ingresso por ramo}

O gráfico 6 reflecte a preferência dos jovens que se mostraram favoráveis ao ingresso em cada um dos ramos e permite concluir que $50 \%$ dos jovens assumem que, em caso de ingresso, teriam preferência pelo Exército. Em segundo lugar, em termos de preferência, surge a Força Aérea $(26,4 \%)$ e, por último, a Marinha, com uma percentagem de 17,6\%. De salientar que apenas $6 \%$ dos jovens que afirmaram estar predispostos a ingressar mostram indefinição quanto ao ramo de preferência.

Gráfico 6: Ramo de preferência para ingresso

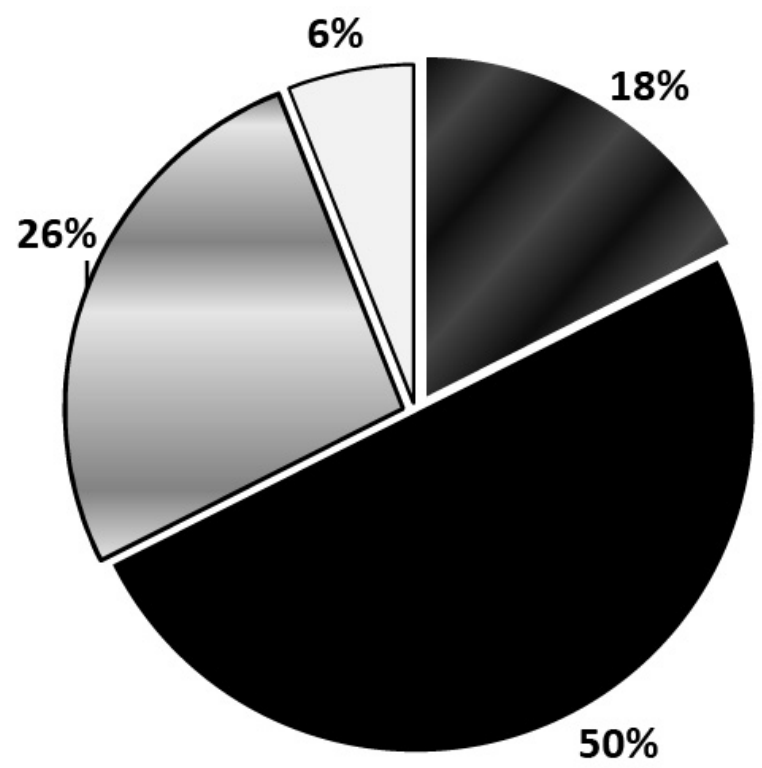

varinha

Exército

घForça Aérea

$\square$ Sem preferência

N $=27294$

FONTE: MDN/DGPRM - BD DDN: 04/07 


\section{b) Influência da escolaridade na preferência do ramo}

No que respeita à variação das características dos jovens em função do ramo de preferência para ingresso, o Gráfico 7 revela que as habilitações escolares dos jovens que se mostram predispostos a ingressar nos três ramos são significativamente diferentes. Comparando os valores totais de pretensão de ingresso em cada um dos ramos com os valores que estes obtêm em cada nível de escolaridade, retiram-se algumas ilações interessantes. Em relação ao Exército (valor médio de 50\%), constata-se que à medida que a escolaridade aumenta, diminui o número de jovens que atrai, sendo que obtém valores inferiores ao seu valor médio junto dos jovens que têm o $12 .{ }^{\circ}$ ano ou frequência universitária, $45,1 \%$ e $35,0 \%$, respectivamente. Contudo, até ao $12 .$. ano de escolaridade é o ramo com maior poder de atracção. No que concerne à Força Aérea (com $26,4 \%$ de preferência para ingresso), o movimento de evolução dos dados é claramente inverso ao registado para o Exército, uma vez que, à medida que o nível de escolaridade é mais elevado, aumenta o interesse em efectivar o ingresso nas Forças Armadas através deste ramo. Aliás, no que respeita ao segmento de jovens que tem frequência de ensino superior, a Força Aérea consegue ser o ramo mais atractivo em termos de preferência para ingresso $(40,1 \%)$. Relativamente à Marinha não se verificam diferenças muito significativas na predisposição dos jovens para o ingresso neste ramo em função do nível habilitacional dos mesmos.

\section{Gráfico 7: Variação do ramo de preferência para ingresso em função da escolaridade}

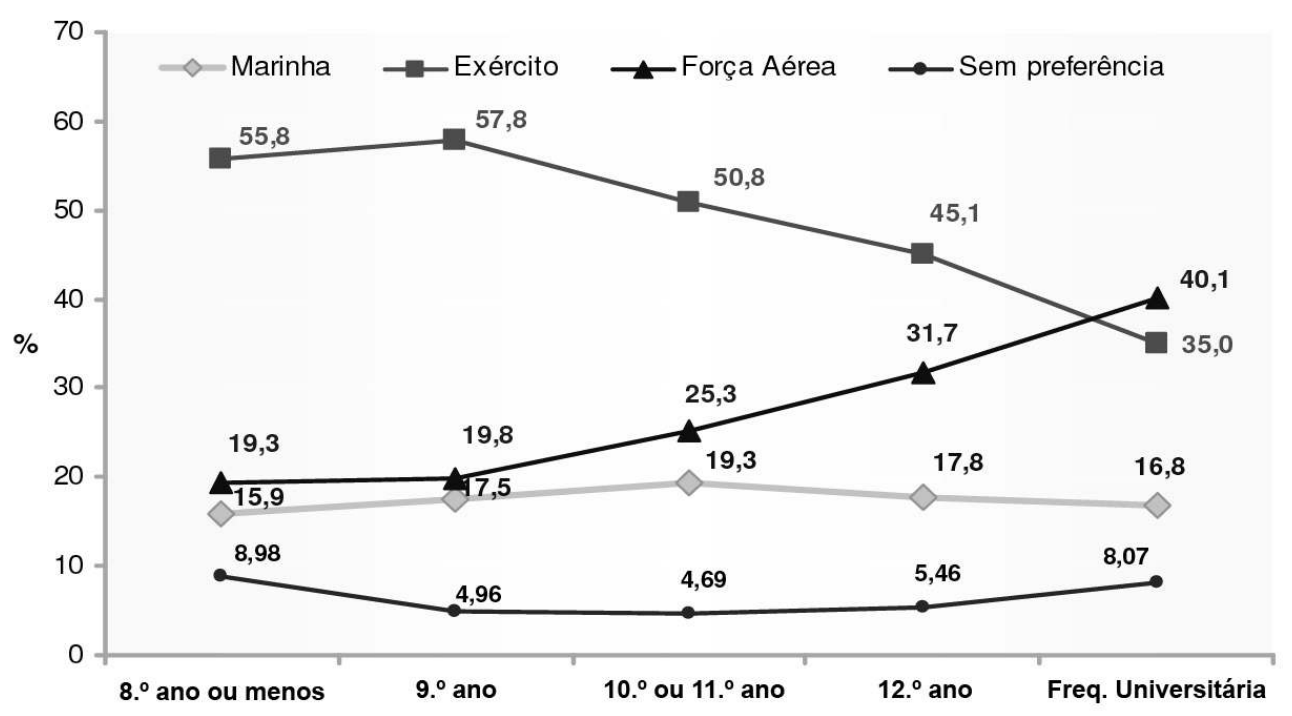

$\mathbf{N}=27294$

FONTE: MDN/DGPRM - BD DDN: 04/07

Importa referir ainda, em matéria de influência da escolaridade na escolha do ramo de preferência, que os dados aqui apresentados revelam o mesmo padrão de configuração desde o primeiro ciclo do Dia da Defesa Nacional, pelo que se trata de uma regularidade que não pode deixar de se constituir como objecto de reflexão por parte das estruturas dirigentes das Forças Armadas. 


\section{c) Motivos justificativos da decisão de ingresso nas Forças}

\section{Armadas}

As razões elencadas para justificar o ingresso abrangeram aspectos simbólicos ligados à própria natureza das Forças Armadas (como as características da vida militar, a vocação profissional ou a possibilidade de participação em Missões de Apoio à Paz) e motivos de cariz instrumental (como a existência de incentivos atractivos ou a possibilidade de concorrerem aos quadros permanentes das Forças Armadas e Forças de Segurança). Os resultados obtidos encontram-se expressos no Quadro 5 e permitem verificar que os motivos mais referidos para justificar a pretensão de ingresso nas Forças Armadas são a vontade de participar em Missões de Apoio à Paz (37,5\%), a vontade de adquirir formação profissional (35,9\%), as características da vida militar (32,7\%), a atractividade dos incentivos (22\%) e a possibilidade de concorrer ao Quadro Permanente das Forças Armadas $(21,1 \%)$. Importa ainda referir que a percentagem de jovens que justifica o ingresso nas Forças Armadas por aquilo que se pode definir por falta de oportunidades alternativas é residual, situando-se à volta dos $4 \%$.

Quadro 5: Motivos apontados para o ingresso nas Forças Armadas

\begin{tabular}{|l|l|}
\hline Motivos de Ingresso $^{3}$ & $\%^{3}$ \\
\hline Vocação Profissional & 14 \\
\hline Concorrer ao QP das Forças Armadas & 21,1 \\
\hline Prestígio Social dos Militares & 15 \\
\hline Concorrer ao QP das Forças de Segurança & 10 \\
\hline Incentivos Atractivos & 22 \\
\hline Participar em Missões de Apoio à Paz & 37,5 \\
\hline Adquirir Independência Económica e Familiar & 18,5 \\
\hline Adquirir Formação Profissional & 35,9 \\
\hline Concorrer ao QP da Função Pública & 5,8 \\
\hline Características da Vida Militar & 32,7 \\
\hline Não ter emprego & 4,5 \\
\hline Não conseguir arranjar outro emprego & 4,2 \\
\hline
\end{tabular}

FONTE: MDN/DGPRM - BD DDN: 04/07

Com o intuito de melhor compreender os motivos de ingresso nas Forças Armadas, estes foram sujeitos a uma análise de correspondências múltiplas. No entanto, importa 
salientar que acima de tudo se pretende compreender que motivos de ingresso surgem associados e têm poder distintivo.

GRÁfico 8: Perfis de Motivos de Ingresso combina as duas dimensões, ou seja, um ingresso pela adesão a valores, mas também com um propósito de instrumentalização, protagonizado pelos inquiridos que justificam o seu ingresso pela atractibilidade do regime de incentivos que é proposto e pela possibilidade de acréscimo das suas qualificações profissionais. Por último, a leitura desta figura não ficaria completa sem que fosse aludida a localização no plano da Marinha e da Força Aérea. De facto, estes dois ramos não surgem como muito distintivos em matéria de perfil de motivos, mas é interessante verificar que se situam num quadrante oposto ao do Exército e claramente na zona positiva da dimensão de utilização.

\section{Conclusões}

Como primeira nota conclusiva relativamente à relação dos jovens participantes no Dia da Defesa Nacional com as Forças Armadas, destaca-se a positividade das 
representações, tanto nos domínios de conteúdo que se prendem com a vertente institucional, como nos que reportam à apreciação do emprego proposto. Trata-se ainda de uma positividade que se tem revelado estável ao longo dos ciclos de estudos, o que, tendo em conta que se trata de uma instituição não muito presente no universo relacional ou simbólico dos jovens, merece algum realce. Contudo, apesar desta positividade geral, detectaram-se algumas variações que, até por serem recorrentes, importa realçar, nomeadamente a influência do nível de escolaridade dos jovens, donde se extrai que a população com escolaridade mais elevada tende a manifestar representações menos positivas face às Forças Armadas, sem que se cheguem a atingir valores negativos.

No que concerne à predisposição para o ingresso nas Forças Armadas, desde que se iniciaram os estudos no âmbito do Dia da Defesa Nacional, o actual ciclo foi o que registou o valor mais elevado de predisposição para ingresso (aproximadamente 53\%), o que, do ponto de vista quantitativo, se pode considerar como um bom indicador em matéria de sustentabilidade do modelo de profissionalização das Forças Armadas. Um outro dado quantitativo que se pode considerar relevante prende-se com o facto de um número muito significativo de jovens que se manifestaram predispostos a ingressar pretenderem fazê-lo num intervalo de tempo que não ultrapassa os 12 meses após a participação no Dia da Defesa Nacional (33,4\%).

Do ponto de vista qualitativo, foi possível identificar os principais traços do perfil dos jovens que manifestam predisposição para ingressar nas Forças Armadas, no qual os menos escolarizados (com escolaridade que não ultrapassa o 11..$^{\circ}$ ano) revelam valores de predisposição significativamente mais elevados que os mais escolarizados (com o 12.ำ ano ou frequência de ensino superior). Trata-se de uma situação algo expectável, dado que os jovens que projectam percursos escolares que passam pela conclusão de estudos de nível superior tenderão a colocar menos a possibilidade de conciliar esses propósitos com um ingresso no mercado de trabalho, seja através das Forças Armadas ou outra entidade empregadora.

46 Ainda em matéria de escolaridade, foi possível verificar que cada um dos ramos enfrenta situações diversas, sendo que os jovens que manifestam preferência para ingresso na Força Aérea tendem a ser mais escolarizados do que os que preferem os restantes ramos, sobretudo o Exército.

47 Como complemento da informação relativa ao perfil dos jovens interessados no ingresso em cada um dos ramos, foi também possível identificar os principais motivos em que assenta a justificação dessa pretensão, bem como a sua diferenciação consoante o ramo pretendido. Os dados permitiram dar conta de que à pretensão de ingresso no Exército estão associados motivos relacionados com a atractividade das características da vida militar, à participação em missões de apoio à paz, ao passo que o ingresso na Marinha e na Força Aérea tem subjacentes interesses que indicam a utilização das Forças Armadas como meio para atingir outros patamares, sejam eles de ingresso num quadro permanente, sejam de aumento das qualificações.

No que concerne aos factores que explicam a variação da predisposição para ingresso nas Forças Armadas, o modelo de regressão utilizado clarifica de forma segura a importância que as representações assumem nesta matéria, tratando-se da dimensão com influência mais significativa e de sentido positivo. A rede social em que os jovens se inserem, nomeadamente a frequência com que falam das Forças Armadas com familiares e amigos, também revela uma influência significativa e positiva, mas de 
intensidade muito menor. Por último, relativamente a esta temática, verificou-se que a escolaridade dos jovens apresenta uma influência directa não muito intensa, quando comparada por exemplo com as representações, mas ainda assim significativa e de sentido negativo. Trata-se, aliás, de um sentido de influência recorrente, uma vez que também se manifesta na apreciação do próprio Dia da Defesa Nacional e seus componentes, bem como na explicação das representações sobre as Forças Armadas. Esta recorrência permite constatar que o grupo de jovens mais escolarizados não só tende a considerar menos as propostas de emprego apresentadas pelas Forças Armadas, mas também a apreciar de forma menos positiva o que estas representam e os eventos que promovem. Trata-se de um dado que se pode considerar incontornável em matéria de definição de estratégias de comunicação por parte das Forças Armadas, sejam elas de informação, sensibilização ou de recrutamento.

Processo de recolha de dados - Outubro de 2004 a Junho de 2007.

\section{BIBLIOGRAFIA}

BATTISTELLI, F. (2004), “Os militares e os desafios da pós-modernidade: o caso italiano”, Revista Nação e Defesa, 107, Lisboa, Instituto da Defesa Nacional.

BENOÎT-GUILBOT, O. e J.-V. Pfirsch (1998), La decision d'engagement volontaire des militaires du rang: L'armée de terre, Paris, Centre d'Études en Sciences Sociales de la Défense.

BOENE, B. (2003), “La professionnalisation des armées”, Revue française de sociologie, 44-4, Paris, Ophrys.

DUBAR, C. (1997), A Socialização - construção de identidades profissionais, Porto, Porto Editora.

LABATUT, B. e J. Martinez Paricio (2003), La professionnalisation des armées en Espagne: consequences des mutations du système d'hommes sur la politique militaire et sur les relations civilo-militaires, Paris, Centre d'Études en Sciences Sociales de la Défense.

LADA, E. e C. Nicole-Drancourt (1998), Images de l'armée et insertion des jeunes, Paris, Centre d'Études en Sciences Sociales de la Défense.

LÉGER, J.-F. (2003), “Les Jeunes engagés”, Revue française de sociologie, 44-4, Paris, Ophrys.

MARICHY, J. P. (2003), Cinq ans aprés, que sont devenues les engagés volontaires de l'armée de terre, Paris, Centre d'Études en Sciences Sociales de la Défense.

\section{NOTAS}

1. Escala de graduação crescente de 1 a 7 valores.

2. Escala de concordância crescente de 1 a 7 valores.

3. Cada item totaliza $100 \%$. 


\section{RESUMOS}

Nas sociedades actuais qualquer instituição, entre elas a militar, não é mais julgada pelo que se propõe fazer, mas pelo que efectivamente faz. Tratadas pela sociedade e pelo mercado como qualquer outra instituição, as Forças Armadas estão, assim, mais sujeitas ao escrutínio e controlo social. Cultivar a legitimidade tornou-se cada vez mais uma necessidade, tendo em vista a prevenção de possíveis situações de banalização institucional. Além desta atitude de cariz próactivo, os pressupostos da profissionalização, enquanto novo modelo de organização, também lhes exigem uma permanente capacidade para conseguir obter os recursos humanos necessários ao desenvolvimento das suas missões.

Para contribuir para a construção de estratégias solidificadas de intervenção neste domínio, torna-se necessário recolher elementos que permitam traçar um diagnóstico da situação, o que implica, forçosamente, considerar como objecto de análise as inter-relações estabelecidas entre as Forças Armadas e a sociedade envolvente. É neste quadro que se insere este estudo, que, a coberto da realização do Dia da Defesa Nacional, procura apreender e caracterizar o que pensa das Forças Armadas e das suas ofertas de emprego um dos segmentos populacionais mais importantes no contexto da profissionalização, ou seja, a população jovem.

In current society, any institution, including the military, is not judged by what they intent to do, but by what they actually do. Judged by the society and job market like any other institution, the Armed Forces are under an exhaustive evaluation and social control. In this context, in order to prevent any situations of institutional trivialization is essential that Armed Forces promote their social legitimacy. In addition to this proactive approach of maintaining the legitimacy, the assumptions inherent to professionalization as a model of military organization, it also requires a permanent ability to attract sufficient human resources to develop and accomplish their missions.

To develop and implement intervention strategies in this domain is essential to analyse and understand the reality, considering the conceptual interplay between the Armed Forces and the involving society. Based on this theoretical conceptualization, the present study aims to collect and understand the perceptions of the young people who attended the National Defence Day regarding the Armed Forces and their job opportunities.

\section{ÍNDICE}

Palavras-chave: Forças Armadas, profissionalização, representações, recrutamento, jovens

Keywords: Armed Forces, professionalization, perceptions, recruitment, youth

\section{AUTORES}

\section{ANTÓNIO IDEIAS CARDOSO}

antonio.cardoso@defesa.pt

\section{ISABEL MADEIRA}

Divisão de Ensino e Formação - Direcção-Geral de Pessoal e Recrutamento Militar (MDN) 


\section{CRISTINA POÇAS VILHENA}

Divisão de Ensino e Formação - Direcção-Geral de Pessoal e Recrutamento Militar (MDN)

LUÍS VICENTE BAPTISTA

FCSH-UNL, CesNova

JOSÉ MANUEL RESENDE

FCSH-UNL, CesNova

PAULO ANTUNES FERREIRA

Investigador do CesNova 